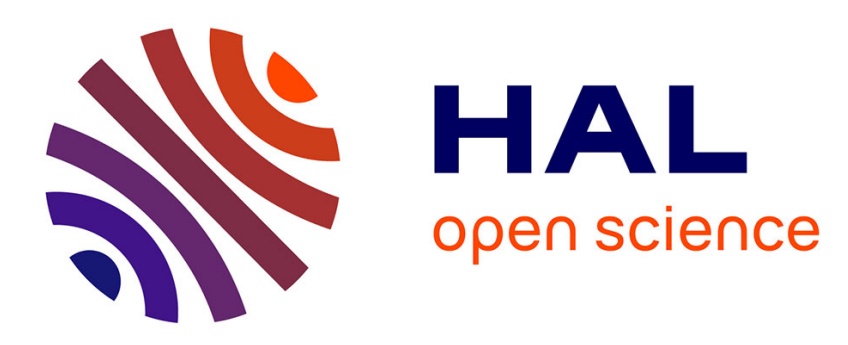

\title{
Enhanced quantum sieving of hydrogen isotopes via molecular rearrangement of the adsorbed phase in chabazite
}

Bastien Radola, Igor Bezverkhyy, Jean-Marc Simon, José Marcos Salazar, Mathieu Macaud, Jean-Pierre Bellat

\section{To cite this version:}

Bastien Radola, Igor Bezverkhyy, Jean-Marc Simon, José Marcos Salazar, Mathieu Macaud, et al.. Enhanced quantum sieving of hydrogen isotopes via molecular rearrangement of the adsorbed phase in chabazite. Chemical Communications, 2020, 56 (41), pp.5564-5566. 10.1039/D0CC02060E . hal03006850

\section{HAL Id: hal-03006850 \\ https://hal.science/hal-03006850}

Submitted on 30 Nov 2020

HAL is a multi-disciplinary open access archive for the deposit and dissemination of scientific research documents, whether they are published or not. The documents may come from teaching and research institutions in France or abroad, or from public or private research centers.
L'archive ouverte pluridisciplinaire HAL, est destinée au dépôt et à la diffusion de documents scientifiques de niveau recherche, publiés ou non, émanant des établissements d'enseignement et de recherche français ou étrangers, des laboratoires publics ou privés. 


\title{
Journal Name
}

\section{ARTICLE TYPE}

\section{Cite this: DOI: 00.0000/xxxxxxxxxx \\ Enhanced Quantum Sieving of Hydrogen Isotopes via Molecular Rearrangement of the Adsorbed Phase in Chabazite $^{\dagger}$}

\author{
Bastien Radola, ${ }^{a}$ Igor Bezverkhyy, ${ }^{a}$ Jean-Marc Simon, ${ }^{a}$ José Marcos Salazar, ${ }^{a}$ Math- \\ ieu Macaud, ${ }^{b}$ and Jean-Pierre Bellat ${ }^{* a}$
}

Received Date

Accepted Date

DOI: $00.0000 / x x x x x x x x x x$
Coadsorption experiments reveal an unexpected increase of the $D_{2} / H_{2}$ selectivity with loading in pure silica chabazite at $47 \mathrm{~K}$. This effect is correlated with the appearance of a step in the adsorption isotherms of $\mathrm{H}_{2}$ and $\mathrm{D}_{2}$. Grand canonical Monte Carlo simulations show that this phenomenon is related to a molecular rearrangement of the adsorbed phase induced by its strong confinement. In the case of a $\mathrm{H}_{2}$ and $D_{2}$ mixture, this rearrangement favors the adsorption of $D_{2}$ having a smaller size due to quantum effects.

Hydrogen isotope separation plays an important role in modern industrial applications, particularly in the nuclear industry where it will have an even greater importance with the advent of nuclear fusion technology. Historically, it was accomplished by cryogenic distillation or by Girdler method but their separation efficiency is rather low. ${ }^{1}$ Recently, an alternative approach based on the adsorption in nanoporous solids has been proposed. This technique relies on the "quantum sieving" effect which takes place at cryogenic temperatures $(<100 \mathrm{~K})$ when the size of the molecules is close to the pore diameter. ${ }^{23}$ Under these conditions, the effective molecular radius of $\mathrm{H}_{2}$ is larger than those of its heavier isotopes, resulting in their preferential adsorption.4 6

A number of coadsorption studies on zeolites ${ }^{7-10}$ and metal organic frameworks (MOFs) ${ }^{11}-14$ reported $\mathrm{D}_{2} / \mathrm{H}_{2}$ selectivity values higher than one, which indicates a preferential adsorption of $\mathrm{D}_{2}$. These values are high at low loading and decline as the adsorbed amount increases. This effect implies that such adsorbents are poorly suitable for industrial separations which are usually re-

\footnotetext{
a Laboratoire Interdisciplinaire Carnot de Bourgogne (ICB), UMR 6303 CNRS/Université de Bourgogne Franche-Comté, F-21078 Dijon, France. E-mail: jean-pierre.bellat@u-bourgogne.fr

${ }^{b}$ CEA, DAM, Valduc, F-21120 Is-sur-Tille, France.

$\dagger$ Electronic Supplementary Information (ESI) available: details of the experimental methods including sample characterization, simulation details and additional simulation results. See DOI: 00.0000/00000000.
}

alized at high loading. As suggested by molecular simulations, the increase of $\mathrm{D}_{2} / \mathrm{H}_{2}$ selectivity with loading might be achieved under strong confinement of the adsorbed phase in small pore zeolites $\frac{15}{15}$ or carbon nanotubes 16 . Recently, such effect has been observed experimentally in ultramicroporous MOFs at $20 \mathrm{~K}$, below the boiling points of $\mathrm{H}_{2}$ and $\mathrm{D}_{2}$, and only for low loadings $\left(1-2 \mathrm{mmol} \mathrm{g}^{-1}\right) \underline{17} 18$

In the present communication, we report an increase of the $\mathrm{D}_{2} / \mathrm{H}_{2}$ selectivity with pressure in pure silica chabazite at $47 \mathrm{~K}$ for high loadings $\left(>10 \mathrm{mmolg}^{-1}\right)$. As far as we know, this phenomenon has never been reported in the literature. Moreover, the mechanism governing this effect is elucidated by grand canonical Monte Carlo (GCMC) simulations. Based on a detailed analysis of the simulation data, we advance an explanation of the increase of selectivity which results from the rearrangement of the adsorbed phase associated with its strong confinement.

The structure and properties of the pure silica chabazite as well as the details of the experimental techniques used in this work are described in ESI. ${ }^{\dagger}$ In the GCMC simulations, we used our own force field developed for pure silica zeolites. As in previous works devoted to zeolites, 19,22 the quantum effects emerging at cryogenic temperatures were taken into account by the $4^{\text {th }}$ order Feynman-Hibbs effective interaction potential. ${ }^{23 \mid 24}$ The zeolite framework was kept rigid during the simulations. See $\mathrm{ESI}^{\dagger}$ for additional details about the simulation methods.

Figure 1 reports $\mathrm{H}_{2}$ and $\mathrm{D}_{2}$ single gas adsorption isotherms measured and simulated at $47 \mathrm{~K}$ and $77 \mathrm{~K}$ in the $1-100000 \mathrm{~Pa}$ pressure range. At $77 \mathrm{~K}$, our simulations reproduce perfectly the shape and the adsorbed amounts. At $47 \mathrm{~K}$, a striking feature is the presence of a step in the adsorption isotherms. In the experimental curves, the step starts at $\sim 1000 \mathrm{~Pa}$ for $\mathrm{D}_{2}$ and at $\sim 10000 \mathrm{~Pa}$ for $\mathrm{H}_{2}$. The simulations reproduce correctly this behavior but with the positions of the steps shifted to $\sim 2000 \mathrm{~Pa}$ for $\mathrm{D}_{2}$ and $\sim 30000 \mathrm{~Pa}$ for $\mathrm{H}_{2}$. Interestingly, the step occurs at the same load- 


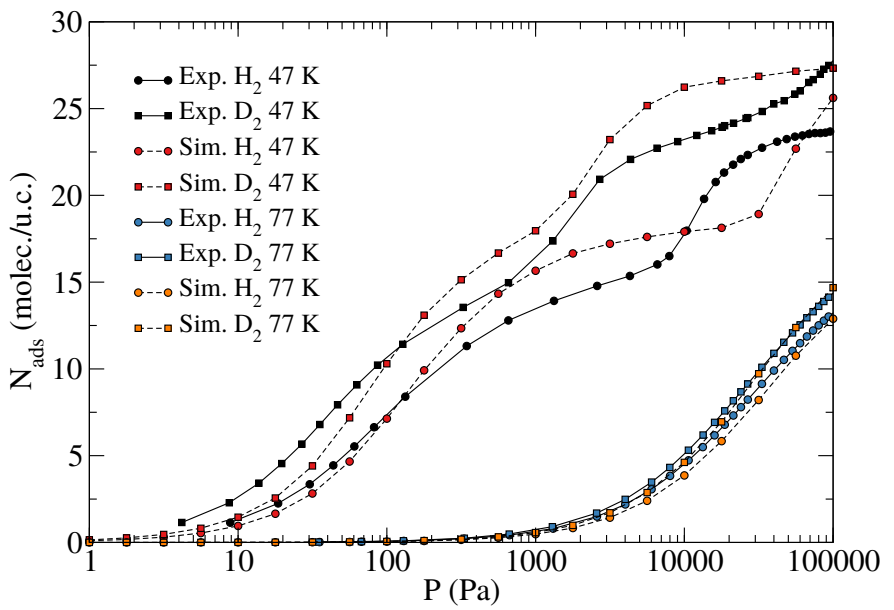

Fig. 1 Experimental and simulated adsorption isotherms of single $\mathrm{H}_{2}$ and $\mathrm{D}_{2}$ in pure silica chabazite at $47 \mathrm{~K}$ and $77 \mathrm{~K}$.

ing for both species, at a value of 15-18 molecules per unit cell (6.9-8.3 $\mathrm{mmol} \mathrm{g}^{-1}$ ). The presence of a step in the adsorption isotherms can be explained either by a flexibility of the adsorbent or by a rearrangement of the adsorbed phase. Given that we used a rigid zeolite structure in our simulations, the rearrangement of the adsorbed phase appears to be the most plausible hypothesis, as it will be shown in the following.

The simulation results presented in figure 1 were obtained with the unit cell parameters of chabazite determined at room temperature. However, this zeolite is known to have a large negative thermal expansion coefficient. $\frac{25}{25}$ The only available values of this coefficient have been determined in the 293-873 K temperature range. Nonetheless, we carried out additional simulations with an expanded chabazite unit cell. The increase of the cell parameters has only a small influence on the maximum adsorption capacities. In contrast, the position of the steps in the simulated isotherms become closer to the experimental ones (see ESI, ${ }^{\dagger}$ figure S4).

To investigate the mechanism giving rise to the step in the isotherms, a density profile analysis of the adsorbed molecules inside the chabazite pores was done. The results are plotted in figure 2 as a function of the distance from the center of the octagonal windows (see the schematic representation of the chabazite structure in figure 3). It can be seen that before the step (dashed lines) only two peaks are visible, corresponding to molecules adsorbed inside the cages at a $2 \AA$ distance from the centers of the octagonal windows. Only a very small fraction of the molecules is located at the window centers. After the step (solid lines), these sites become heavily populated as evidenced by the appearance of a high central peak. Moreover, the two other peaks, already observed before the step, are displaced at a 3-3.5 $\AA$ distance from the octagonal window centers. Thus, this rearrangement is related to the appearance of molecules at the window centers, which repel the surrounding molecules. In consequence, a denser adsorbed phase is formed as evidenced by the analysis of the snapshots and the pair radial distribution functions (see ESI, ${ }^{\dagger}$ figures S5 and S6).

To understand how the adsorbed phase rearrangement influences the $\mathrm{D}_{2} / \mathrm{H}_{2}$ selectivity, we carried out GCMC simulations and coadsorption experiments of a $3: 1 \mathrm{H}_{2}+\mathrm{D}_{2}$ mixture at $47 \mathrm{~K}$

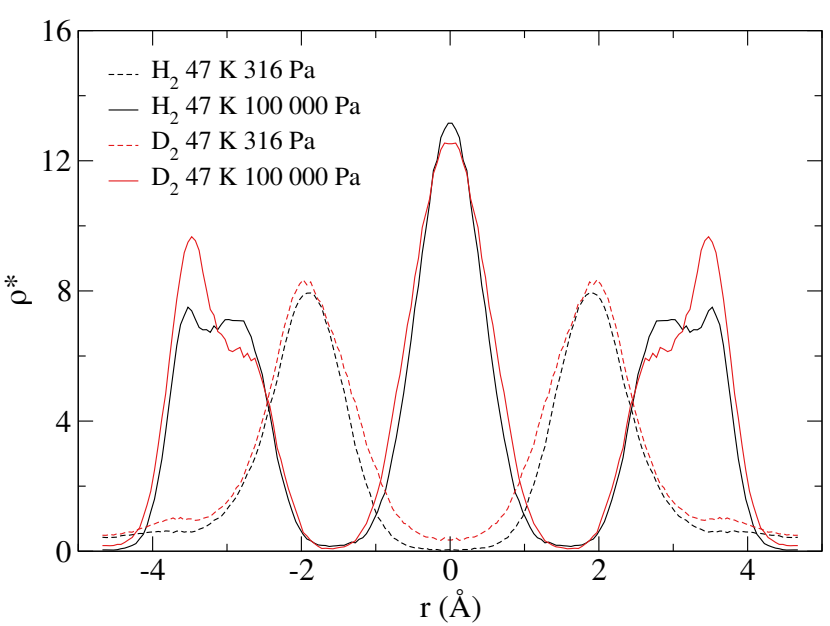

Fig. 2 Density profiles of $\mathrm{H}_{2}$ and $\mathrm{D}_{2}$ molecules in the single gas adsorption case in pure silica chabazite at a temperature of $47 \mathrm{~K}$, both before the step $(P=316 \mathrm{~Pa}$, dashed lines $)$ and after the step $(P=100000 \mathrm{~Pa}$, solid lines). The density profiles are computed on small cylinders distributed along an axis going from the center of a cage $(r=-4.65 \AA)$ to the center of a neighboring cage $(r=4.65 \AA)$ and passing through the octagonal window separating them $(r=0 \AA)$. The diameter of these cylinders is chosen to be $3.72 \AA$, corresponding to the size of the windows. The density $\rho^{*}$ is normalized by a reference value, arbitrarily chosen as the average density of $D_{2}$ molecules adsorbed at $47 \mathrm{~K}$ and $100000 \mathrm{~Pa}$.

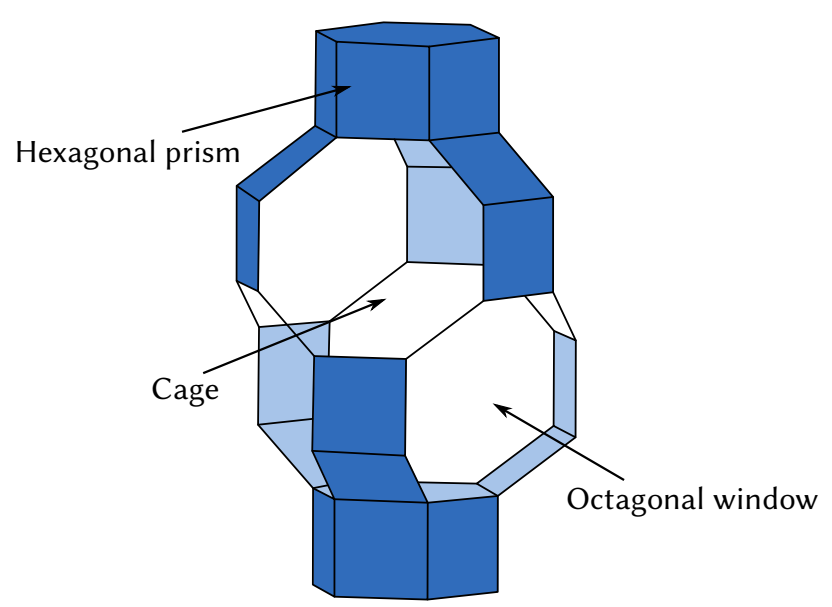

Fig. 3 Schematic representation of the chabazite structure, composed of two sub-units: hexagonal prisms and cages. Only the latter are accessible to adsorbed molecules, which can diffuse through the octagonal windows. For the sake of clarity, the inaccessible pores and windows are rendered in opaque blue. Note that a unit cell of chabazite is composed of 3 cages and 3 hexagonal prisms and its chemical composition is $\left(\mathrm{SiO}_{2}\right)_{36}$ for the pure silica variant. 


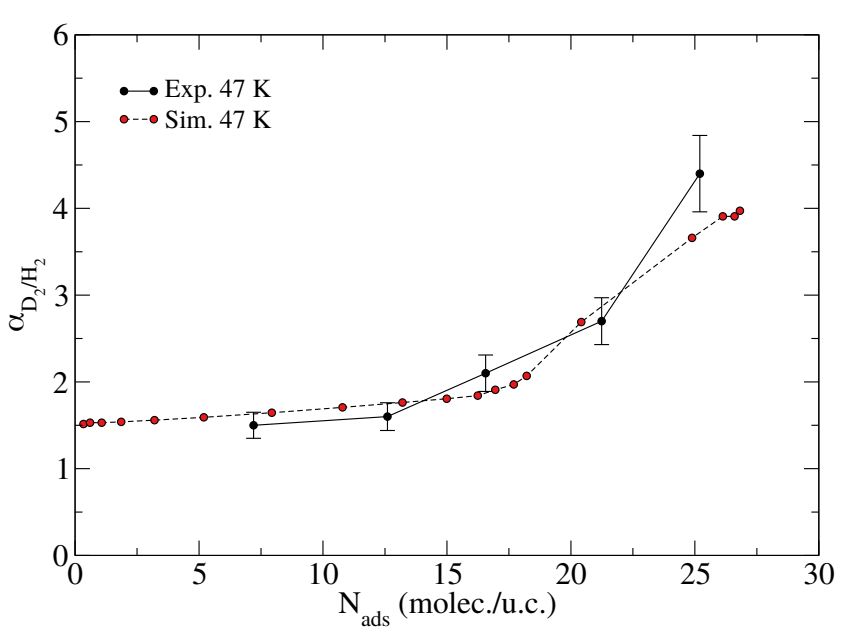

Fig. 4 Experimental (solid lines) and simulated (dashed lines) adsorption selectivity of $D_{2}$ towards $H_{2}$ in pure silica chabazite at $47 \mathrm{~K}$. This value is calculated as the ratio of the molar fractions of $D_{2}$ in the adsorbed and gas phases, respectively, divided by the same ratio for $\mathrm{H}_{2}$.

(see $\mathrm{ESI}^{\dagger}$ for details). The $\mathrm{D}_{2} / \mathrm{H}_{2}$ selectivity values are plotted in figure 4 as a function of the total adsorbed quantities per unit cell. The simulated data exhibit an excellent agreement with the experimental ones. For a loading below 18 molecules per unit cell $\left(8.3 \mathrm{mmol}^{-1}\right)$, the selectivity slowly increases from a value of 1.5 at zero loading to 1.9. Above this threshold value, corresponding to the start of the step in the adsorption isotherms (see figure 1), the selectivity increases promptly to a maximum of 4.0 at complete saturation of the microporous volume. Namely, for a loading of 27 molecules per unit cell $\left(12.5 \mathrm{mmol} \mathrm{g}^{-1}\right)$.

To investigate this effect, as previously done for single gases, density profiles are calculated and given in figure 5 before and after the step. The rearrangement observed when the pressure increases is quite similar to that obtained in the single component adsorption case discussed above. The effect on the $\mathrm{D}_{2} / \mathrm{H}_{2}$ selectivity is directly visible on these density profiles. Specifically, before the step, a 2:1 density ratio between $\mathrm{H}_{2}$ and $\mathrm{D}_{2}$ can be calculated from the intensities of the peaks compared to a 3:1 ratio in the gas phase. After the step, the same adsorption sites inside the cages become even more selective, with an almost 1:1 density ratio. The most remarkable feature concerns the new sites located at the window centers, where the $\mathrm{D}_{2}$ density is about three times greater than the $\mathrm{H}_{2}$ one.

Based on our density profile analyses, we can attribute this selectivity increase to a strong confinement effect in chabazite pores with filling. Indeed, after the step in the adsorption isotherm, the adsorbed phase becomes denser due to the repulsion effect of the molecules located at the window centers. This strong confinement favors the adsorption of $\mathrm{D}_{2}$ molecules which have a smaller effective size than $\mathrm{H}_{2}$ due to quantum effects. 4

Our study evidences a novel effect consisting in the increase of the $\mathrm{D}_{2} / \mathrm{H}_{2}$ selectivity at high loading in pure silica chabazite at $47 \mathrm{~K}$. Based on GCMC simulations, we show that this phenomenon is produced by the rearrangement of the adsorbed phase that increases its confinement. Thus, we can conclude that in quantum sieving the window size is not the only important

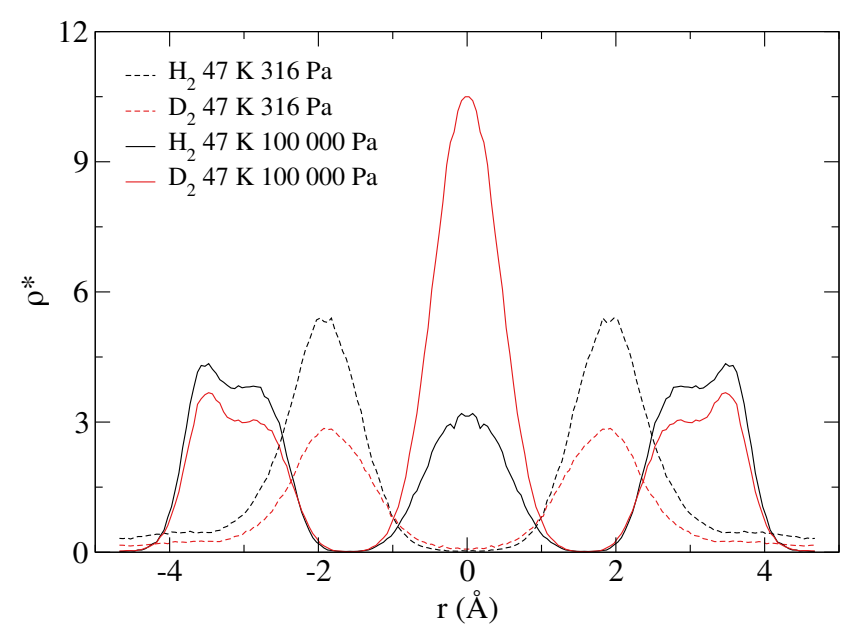

Fig. 5 Density profiles of adsorbed molecules for a $3: 1$ ratio $H_{2}+D_{2}$ mixture in pure silica chabazite at a temperature of $47 \mathrm{~K}$, both before the step $(P=316 \mathrm{~Pa}$, dashed lines $)$ and after the step $(P=100000 \mathrm{~Pa}$, solid lines). The density profiles are computed in the same way as in the single gas adsorption case (see figure 2 .

parameter. At high loading, the fine balance between the pore geometry and the intermolecular interactions defines the guest molecules packing. In particular, for hydrogen isotopes separation this confinement effect may induce a significant increase of the selectivity in favor of heavier species. This opens new perspectives for the design of more selective nanoporous materials.

\section{Conflicts of interest}

There are no conflicts to declare.

\section{References}

1 Separation of Hydrogen Isotopes, ed. H. K. Rae, American Chemical Society: Washington, D. C., 1978, vol. 68, p. 191.

2 J. Cai, Y. Xing and X. Zhao, RSC Adv., 2012, 2, 8579-8586.

3 H. Oh and M. Hirscher, Eur. J. Inorg. Chem., 2016, 2016, 4278-4289.

4 J. J. M. Beenakker, V. D. Borman and S. Y. Krylov, Chem. Phys. Lett., 1995, 232, 379-382.

5 Q. Wang, S. R. Challa, D. S. Sholl and J. K. Johnson, Phys. Rev. Lett., 1999, 82, 956.

6 S. R. Challa, D. S. Sholl and J. K. Johnson, Phys. Rev. B, 2001, 63, 245419.

7 K. Kotoh and K. Kudo, Fusion Sci. Technol., 2005, 48, 148-151.

8 K. Kotoh, S. Takashima, T. Sakamoto and T. Tsuge, Fusion Eng. Des., 2010, 85, 1928-1934.

9 R. Xiong, R. Balderas Xicohténcatl, L. Zhang, P. Li, Y. Yao, G. Sang, C. Chen, T. Tang, D. Luo and M. Hirscher, Microporous Mesoporous Mater., 2018, 264 22-27.

10 M. Giraudet, I. Bezverkhyy, G. Weber, C. Dirand, M. Macaud and J.-P. Bellat, Microporous Mesoporous Mater., 2018, 270, 211-219.

11 H. Oh, I. Savchenko, A. Mavrandonakis, T. Heine and M. Hirscher, ACS Nano, 2014, 8, 761-770.

12 I. Weinrauch, I. Savchenko, D. Denysenko, S. M. Souliou, H.-H. Kim, M. Le Tacon, L. L. Daemen, Y. Cheng, A. Mavrandonakis, A. J. Ramirez Cuesta, D. Volkmer, G. Schütz, M. Hirscher and T. Heine, Nat. Commun., 2017, 8, 1-7.

13 J. Y. Kim, R. Balderas Xicohténcatl, L. Zhang, S. G. Kang, M. Hirscher, H. Oh and H. R. Moon, J. Am. Chem. Soc., 2017, 139, 15135-15141.

14 J. Y. Kim, L. Zhang, R. Balderas Xicohténcatl, J. Park, M. Hirscher, H. R. Moon and H. Oh, J. Am. Chem. Soc., 2017, 139, 17743-17746.

15 J. Perez Carbajo, J. B. Parra, C. O. Ania, P. J. Merkling and S. Calero, ACS Appl. Mater. Interfaces, 2019, 11, 18833-18840.

16 S. R. Challa, D. S. Sholl and J. K. Johnson, J. Chem. Phys., 2002, 116, 814-824.

17 G. Han, Y. Gong, H. Huang, D. Cao, X. Chen, D. Liu and C. Zhong, ACS Appl. Mater. Interfaces, 2018, 10, 32128-32132.

18 D. Cao, H. Huang, Y. Lan, X. Chen, Q. Yang, D. Liu, Y. Gong, C. Xiao, C. Zhong and S. Peng, J. Mater. Chem. A, 2018, 6, 19954-19959.

19 A. V. A. Kumar, H. Jobic and S. K. Bhatia, J. Phys. Chem. A, 2006, 110, 1666616671. 
20 A. V. A. Kumar, H. Jobic and S. K. Bhatia, Adsorption, 2007, 13, 501-508.

21 J. M. Salazar, S. Lectez, C. Gauvin, M. Macaud, J.-P. Bellat, G. Weber, I. Bezverkhyy and J.-M. Simon, Int. J. Hydrogen Energ., 2017, 42, 13099-13110.

22 J. M. Salazar, M. Badawi, B. Radola, M. Macaud and J.-M. Simon, J. Phys. Chem. C, 2019, 123, 23455-23463.

23 R. P. Feynman and A. R. Hibbs, Quantum Mechanics and Path Integrals, New York: Dover Publications, Inc., 1965, p. 365

24 L. M. Sesé, Molec. Phys., 1995, 85, 931-947.

25 D. A. Woodcock and P. Lighfoot, Chem. Mater., 1999, 11, 2508-2514. 